\title{
Editorial
}

\section{Next-Generation Bio-Products Sowing the Seeds of Success for Sustainable Agriculture}

Gabriele Berg ${ }^{1,2, *}$, Christin Zachow ${ }^{1}$, Henry Müller ${ }^{2}$, Jörg Philipps ${ }^{3}$ and Ralf Tilcher ${ }^{3}$

1 Austrian Center of Industrial Biotechnology (ACIB GmbH), Petersgasse 14, Graz 8010, Austria;

E-Mail: christin.zachow@acib.at

2 Institute of Environmental Biotechnology, Graz University of Technology, Petersgasse 12, Graz A-8010, Austria; E-Mail: henry.mueller@tugraz.at

3 KWS SAAT AG, Grimsehlstraße 31, Einbeck D-37555, Germany;

E-Mails: j.philipps@kws.com (J.P.); r.tilcher@kws.com (R.T.)

* Author to whom correspondence should be addressed; E-Mail: gabriele.berg@tugraz.at;

Tel.: +43-316-873-8423; Fax: +43-316-873-8819.

Received: 1 August 2013; in revised form: 26 September 2013 / Accepted: 8 October 2013 /

Published: 21 October 2013

\begin{abstract}
Plants have recently been recognized as meta-organisms due to a close symbiotic relationship with their microbiome. Comparable to humans and other eukaryotic hosts, plants also harbor a "second genome" that fulfills important host functions. These advances were driven by both "omics"-technologies guided by next-generation sequencing and microscopic insights. Additionally, these new results influence applied fields such as biocontrol and stress protection in agriculture, and new tools may impact (i) the detection of new bio-resources for biocontrol and plant growth promotion, (ii) the optimization of fermentation and formulation processes for biologicals, (iii) stabilization of the biocontrol effect under field conditions, and (iv) risk assessment studies for biotechnological applications. Examples are presented and discussed for the fields mentioned above, and next-generation bio-products were found as a sustainable alternative for agriculture.
\end{abstract}

Keywords: biocontrol; microbiome; microscopy; next-generation bio-product; "omic"-technologies 


\section{Introduction}

\subsection{The Plant as Meta-Organism}

In 1904, more than 100 years ago, Lorenz Hiltner (Munich, Germany) defined the term "rhizosphere" as root-surrounding soil influenced by root exudates [1]. In addition, he discovered the importance of microbial root inhabitants for plant growth and health. Since that time, much has been learned about microorganism and plant host interactions, especially in recent years by means of new next generation sequencing (NGS) techniques, “omics"-technologies, and microscopic methods [2-5]. The rhizosphere is of central importance not only for plant nutrition, health, and quality, but also for microorganismdriven carbon sequestration, ecosystem functioning, and nutrient cycling in terrestrial ecosystems. A multitude of biotic and abiotic factors influence the structural and functional diversity of microbial communities in the rhizosphere [6]. For example, microorganisms' response to root exudates and root morphology was shown to shape rhizosphere microbial communities [7-10]. In addition, plant defense signaling play a role in this process [11].

Soil is the main reservoir for rhizosphere microorganisms [12], and many secrets and theories of microbial life in the rhizosphere were recently uncovered or confirmed due to the enormous progress in molecular and microscopic techniques (Figure 1). Haichar et al. [13] used a stable isotope probing (SIP) approach to show that plant host habitat and root exudates influence the soil bacterial community structure. In another example, Lundberg et al. [14] as well as Bulgarelli et al. [15] revealed that only a subset of the bacterial community in the soil is present around the plant roots of Arabidopsis thaliana. The main root inhabitants represent two bacterial phyla: Proteobacteria, which includes many growth-promoting members, and Actinobacteria, many of which are known for producing antimicrobial compounds. They hypothesized that Arabidopsis recruits a core group of microbes to benefit its basic functions, and an additional subset to help it thrive in specific environments. All these results reveal a new perspective on plants: they are meta-organisms comprised of the plants themselves and all microbial inhabitants.

Not only is the densely colonized rhizosphere important, but each plant is also home to a complex and distinctive community of microbes consisting of billions of inhabitants [16]. Through a comprehensive look at the plant-associated community, hundreds of microbial species were identified as specific to crops, cultivars, and also for the micro-environment. Each plant can be divided into different micro-environments: the endorhiza (root), the phyllosphere (leaves), the spermosphere (seeds), the carposphere (fruit). Moreover, we generally differentiate between the endosphere (inner tissues) and ectosphere (outer surfaces) [17]. All these micro-environments provide specific biotic and abiotic conditions for microbial life. However, an interesting question concerns the origin of the microbial inhabitants on plants as they seem to come from different sources. While soil is the main reservoir for rhizosphere microorganisms, a sub-set of rhizosphere inhabitants is also able to colonize the endorhiza [18]. Endophytes were long believed to originate only from the rhizosphere and soil, but molecular studies have shown that the above ground plant parts can be invaded by microbes as well [18]. New methods also revealed that seeds are colonized not only by (dormant) pathogenic bacteria, but they also harbor a beneficial seed microbiome. In addition, generative organs like pollen [19] and moss sporophytes [20] harbor a core microbiome, containing potential beneficials, e.g., 
diazotrophs. Plants are in constant contact with diverse microbes blown by the wind or delivered via the water, and some of them are able to colonize the phyllosphere.

Figure 1. The plant as natural meta-organism visualized by Fluorescence in situ hybridization (A-C) and confocal laser scanning microscopy: (A) phyllosphere of a Sphagnum leave showing Alphaproteobacteria (yellow) and other bacterial colonies (red), (B) Gammaproteobacteria (yellow) and not taxonomically classified bacteria (red) on pumpkin pollen, $(\mathbf{C})$ bacteria in the rhizosphere of lettuce showing Gammaproteobacteria (yellow) and Betaproteobacteria (pink), and (D) root of an oilseed rape root inoculated by the DsRed-labeled biocontrol agent Pseudomonas trivialis 3Re2-7.
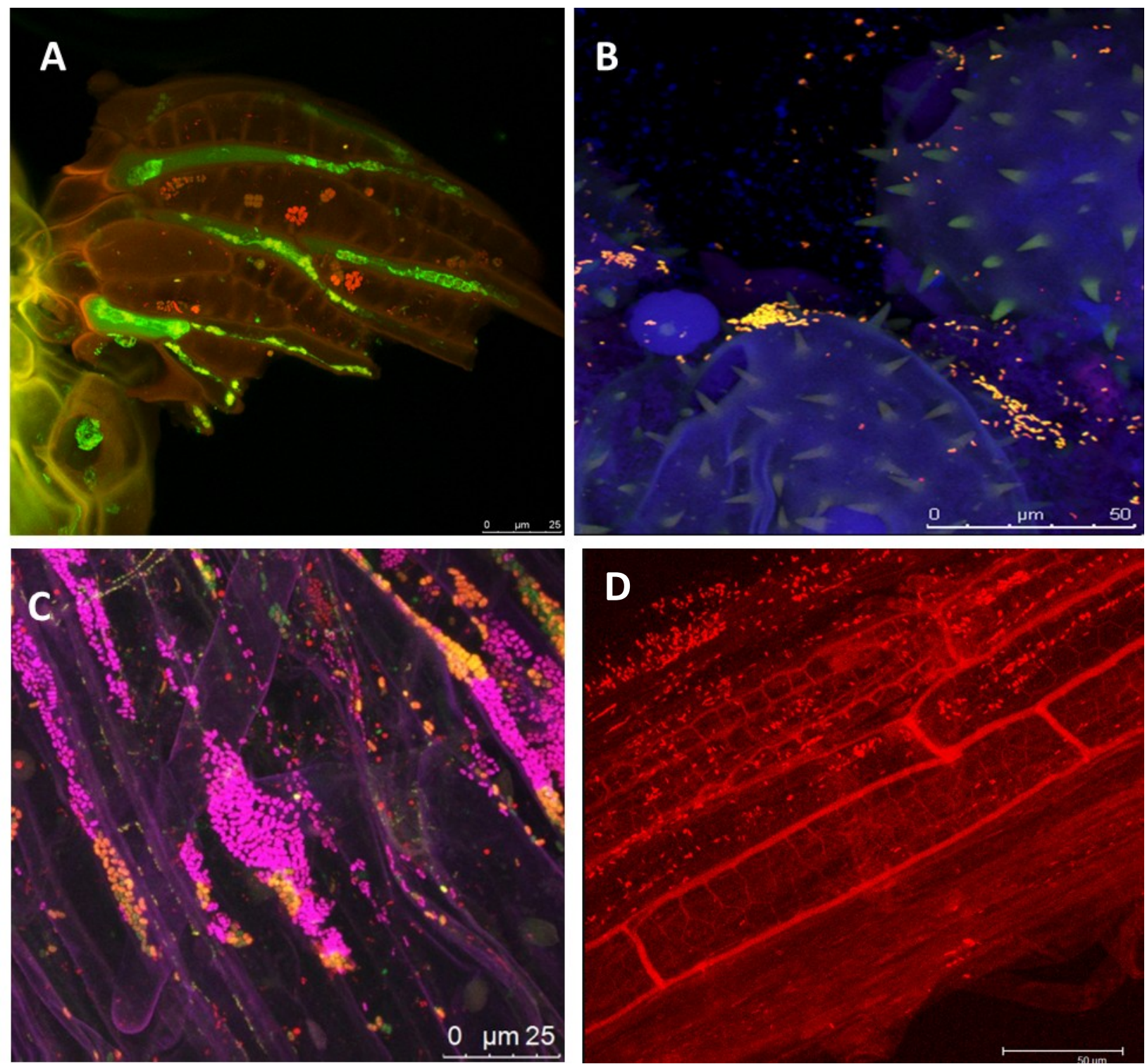

Collectively known as the plant microbiome, plant-associated microbes can help plants fend off disease, stimulate growth, occupy space that would otherwise be taken up by pathogens, promote stress resistance, and influence crop yield and quality. Therefore, the plant microbiome is a key determinant of plant health and productivity. 


\subsection{The Potential of Next-Generation Bio-Products}

Plant microbiome discoveries could fuel advances in sustainable agriculture $[21,22]$, such as the development of microbial inoculants as biofertilizers, biocontrol, or stress protection products [21]. Although we recognize a growing market for these bio-products, they still have their problems, e.g., short shelf-life, inconsistent effects under field conditions, and risk predictions (Figure 2). The application of "omics"-technologies has allowed for an enormous progression in the development of so-called next-generation bio-products [23]. In this field, new tools may have an impact on (i) the detection of new bio-resources for biocontrol and plant growth promoting agents, (ii) the optimization of fermentation and formulation processes for biologicals, (iii) stabilization of the biocontrol effect under field conditions, and (iv) risk assessment studies for biotechnological applications. Several examples are given below.

Figure 2. Knowledge-based and targeted development of next-generation bio-products.

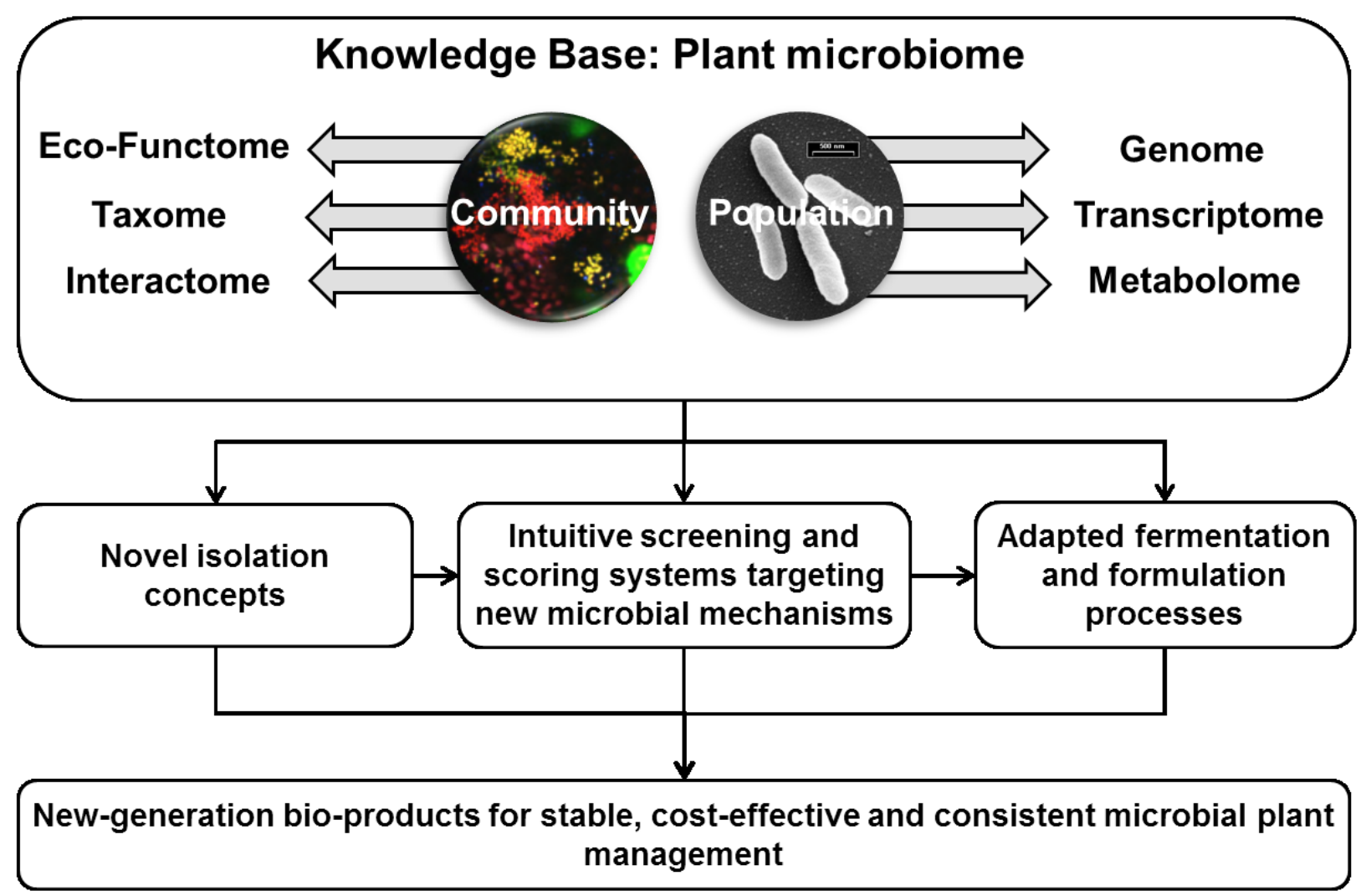

New biocontrol and plant growth promotion agents can be selected from natural environments and other unaffected ecosystems. Natural habitats, especially nature conservation areas, are characterized by a high diversity of plants. Due to the correlation of above- and below-below ground variety, a high microbial diversity can be expected [24]. Moreover, natural habitats have a low number of pathogens, so the general rule of diversity versus pathogenicity would suggest a higher rate of biocontrol and plant growth promotion agents in such environments [25]. This hypothesis was confirmed with high proportions of potential antagonists from such habitats, e.g., associated with mosses [26], with endemic plants from nature conservation areas [27] or with the hemi-parasitic plant mistletoe [28]. Agricultural systems, especially monocultures under intense management, often have a lower 
microbial diversity with the exception of suppressive soils where the microbial community responds to mono-cultivation by enhancing biocontrol and plant growth promotion bacteria against a specific pathogen [29]. These suppressive soils are also an excellent source of new antagonists as already shown for wheat monocultures [30] and intense sugar beet cultivation [31]. Organically managed systems contain a high proportion of indigenous beneficials in comparison to conventional agriculture [32,33], such as the more exotic bio-resource of lichens. These long-living symbiotic meta-organisms often adapt to extreme abiotic conditions and harbor a high proportion of antagonists to protect themselves against fungal parasites [34]. Conversely, Sphagnum mosses are dominant components in ombrotrophic bog ecosystems and are densely colonized by plant growth promoting bacteria. In this nutrient-limited environment, bacteria help the plants survive by providing nitrogen, phosphate, and minerals. In conclusion, it is important to understand the ecological background of ecosystems and the function of the microbiome therein to select sufficient beneficials.

Risk assessments are currently one of the greatest obstacles in bio-product registration [35]. They are cost-intensive, time-consuming, and often inefficient without considering the specific features of bio-products. In order to resolve this issue, an intensive network between administration, industry, and research is required. However, the new tools also influence this field and will hopefully lead to not only a higher registration rate, but also to prevent outbreaks by opportunistic pathogens which are sometimes hidden behind antagonists [36]. Moreover, the NGS techniques can be used (i) to detect potential pathogenicity factors and antibiotic resistances at genomics level, (ii) to analyze the mode of action and involvement of metabolites by transcriptomic studies, (iii) to detect bioactive metabolites at genomic as well as transcriptomic level, and (iv) to study the behavior of biocontrol strains in the environment by amplicon libraries or metagenomics. Here, we present how genome sequencing and correlated transcriptomic studies of the stress protection agent (SPA) Stenotrophomonas rhizophila DSM $14405^{\mathrm{T}}$ have both optimized production processes and identified new potential modes of action and risks factors. This strain has great potential for applications in biotechnology and biological control due to its ability to both promote plant growth and protect roots against biotic and abiotic stresses [37], yet little was known about its mode of action. Antibiotics, lytic enzymes, and osmoprotective substances were previously identified [38,39], but now new mechanisms associated with osmotic stress using a transcriptomic approach have been identified. As such, the production and excretion of glucosylglycerol (GG) were found as mechanisms for the stress protection of this Stenotrophomonas strain [40]. Moreover, spermidine, a plant growth regulator, was also newly identified as a protector against stress. For registration as a stress protection agent, these results are very important. They show that no potential pathogenicity factor is involved in this beneficial plant-microbe interaction. In contrast, the genome of the very closely related plant-associated $S$. maltophilia, which is also an opportunistic pathogen, harbors potential pathogenicity factors. To detect significant differences between both species, we used comparative genomics as well as transcriptomic and physiological approaches [41]. Overall, there is a high degree of sequence similarity between the genomes of the plant and human-associated Stenotrophomonas strains with a notable similarity in potential factors responsible for pathogenicity and antibiotic resistance. However, several virulence factors, heat shock proteins, and antibiotic resistance genes were absent in DSM $14405^{\mathrm{T}}$ but instead possess genes for the synthesis of plant-protective spermidine, plant cell-wall degrading enzymes, and resistance against high salinity. Moreover, bacterial growth at $37{ }^{\circ} \mathrm{C}$ was identified as a very simple 
method to differentiate between the pathogenic and non-pathogenic isolates. DSM $14405^{\mathrm{T}}$ is not able to grow at this human-relevant temperature in comparison to other Stenotrophomonas strains due to the missing heat shock and other unknown proteins. This is an interesting example for predicting the risk of beneficals using a combined approach including "omics"-technologies.

\section{Conclusions}

New perspectives for sustainable agriculture?

1. New tools based on NGS techniques have a high impact on next-generation bio-products. They can improve the detection of new bio-resources for biocontrol and plant growth promoting agents, and also increase their performance and registration efficiency.

2. Plants as meta-organisms create numerous new perspectives for sustainable agriculture, e.g., breeding, seed production, and seed treatment processes.

3. Plants are a hitherto little explored source for new microbes, genes, and bioactive compounds due to the extent of specificity within the plant microbiome.

4. New functions and interactions of plant-associated bacteria can be identified using NGS techniques such as quality enhancement or stress protection.

5. Although, the application of single microorganisms is already successful, information on diversity and specificity of the plant microbiome suggest that microbial consortia or natural microbial transplants, e.g., from suppressive soil, can be more successful as single inoculants.

6. Together, these points open new windows for sustainable agriculture by means of next-generation bio-products. This trend is currently visible in industrial and university research topics.

7. A public dialogue is required in addition to research in order to promote the application of next-generation bio-products in the future for both agriculture and food.

\section{Acknowledgments}

We like to thank Anastasia Bragina, Massimiliano Cardinale Armin Erlacher, and Birgit Lukesch for support with CLSM pictures and Meg Starcher (all Graz) for English revision. This manuscript was supported by different grants of the Austrian Science Foundation FWF (I183-B16; I 882-B16) to G.B. The cooperation of all authors was funded by a project in the Austrian Centre of Industrial Biotechnology, which has been supported by the Austrian BMWFJ, BMVIT, SFG, Standortagentur Tirol and ZIT through the Austrian FFG-COMET-Funding Program.

\section{Conflicts of Interest}

The authors declare no conflict of interest.

\section{References}

1. Hartmann, A.; Rothballer, M.; Schmid, M. Lorenz Hiltner, a pioneer in rhizosphere microbial ecology and soil bacteriology research. Plant Soil 2008, 312, 7-14.

2. Leveau, J.H.J. The magic and menace of metagenomics: Prospects for the study of plant growth-promoting rhizobacteria. Eur. J. Plant Pathol. 2007, 119, 279-300. 
3. Jansson, J.K.; Neufeld, J.D.; Moran, M.A.; Gilbert, J.A. Omics for understanding microbial functional dynamics. Environ. Microbiol. 2012, 14, 1-3.

4. Sorensen, J.; Hauberg Nicolaisen, M.; Ron, E.; Simonet, P. Molecular tools in rhizosphere microbiology-From single-cell to whole-community analysis. Plant Soil 2009, 321, 483-512.

5. Berendsen, R.L.; Pieterse, C.M.; Bakker, P.A. The rhizosphere microbiome and plant health. Trends Plant Sci. 2012, 17, 478-486.

6. Berg, G.; Smalla, K. Plant species and soil type cooperatively shape the structure and function of microbial communities in the rhizosphere. FEMS Microbiol. Ecol. 2009, 68, 1-13.

7. Smalla, K.; Wieland, G.; Buchner, A.; Zock, A.; Parzy, J.; Kaiser, S.; Roskot, N.; Heuer, H.; Berg, G. Bulk and rhizosphere soil bacterial communities studied by denaturing gradient gel electrophoresis: Plant-dependent enrichment and seasonal shifts revealed. Appl. Environ. Microbiol. 2001, 67, 4742-4751.

8. Berg, G.; Zachow, C.; Lottmann, J.; Götz, M.; Costa, R.; Smalla, K. Impact of plant species and site on rhizosphere-associated fungi antagonistic to Verticillium dahliae Kleb. Appl. Environ. Microbiol. 2005c, 71, 4203-4213.

9. Berg, G.; Opelt, K.; Zachow, C.; Lottmann, J.; Götz, M.; Costa, R.; Smalla, K. The rhizosphere effect on bacteria antagonistic towards the pathogenic fungus Verticillium differs depending on plant species and site. FEMS Microbiol. Ecol. 2006, 56, 250-261.

10. Bais, H.P.; Weir, T.L.; Perry, L.G.; Gilroy, S.; Vivanco, J.M. The role of root exudates in rhizosphere interactions with plants and other organisms. Annu. Rev. Plant Biol. 2006, 57, 233-266.

11. Doornbos, R.F.; van Loon, L.C.; Bakker, P.A.H.M. Impact of root exudates and plant defense signaling on bacterial communities in the rhizosphere. Agron. Sustain. 2012, 32, 227-243.

12. Hartmann, A.; Schmid, M.; van Tuinen, D.; Berg, G. Plant-driven selection of microbes. Plant Soil 2009, 321, 235-257.

13. Haichar, F.Z.; Marol, C.; Berge, O.; Rangel-Castro, J.I.; Prosser, J.I.; Balesdent, J.; Heulin, T.; Achouak, W. Plant host habitat and root exudates shape soil bacterial community structure. ISME J. 2008, 2, 1221-1230.

14. Lundberg, D.S.; Lebeis, S.L.; Paredes, S.H.; Yourstone, S.; Gehring, J.; Malfatti, S.; Tremblay, J.; Engelbrektson, A.; Kunin, V.; del Rio, T.G.; et al. Defining the core Arabidopsis thaliana root microbiome. Nature 2012, 488, 86-90.

15. Bulgarelli, D.; Rott, M.; Schlaeppi, K.; Ver Loren van Themaat, E.; Ahmadinejad, N.; Assenza, F.; Rauf, P.; Huettel, B.; Reinhardt, R.; Schmelzer, E.; et al. Revealing structure and assembly cues for Arabidopsis root-inhabiting bacterial microbiota. Nature 2012, 488, 91-95.

16. Vorholt, J.A. Microbial life in the phyllosphere. Nat. Rev. Microbiol. 2012, 10, 828-840.

17. Ryan, R.P.; Germaine, K.; Franks, A.; Ryan, D.J.; Dowling, D.N. Bacterial endophytes: Recent developments and applications. FEMS Microbiol. Lett. 2008, 278, 1-9.

18. Berg, G.; Krechel, A.; Ditz, M.; Sikora, R.A.; Ulrich, A.; Hallmann, J. Endophytic and ectophytic potato-associated bacterial communities differ in structure and antagonistic function against plant pathogenic fungi. FEMS Microbiol. Ecol. 2005, 51, 215-229.

19. Fürnkranz, M.; Lukesch, B.; Müller, H.; Huss, H.; Grube, M.; Berg, G. Microbial diversity inside pumpkins: Microhabitat-specific communities display a high antagonistic potential against phytopathogens. Microb. Ecol. 2012, 63, 418-428. 
20. Bragina, A.; Berg, C.; Cardinale, M.; Shcherbakov, A.; Chebotar, V.; Berg, G. Sphagnum mosses harbour highly specific bacterial diversity during their whole lifecycle. ISME J. 2012, 6, 802-813.

21. Berg, G. Plant-microbe interactions promoting plant growth and health: Perspectives for controlled use of microorganisms in agriculture. J. Appl. Microbiol. Biotechnol. 2009, 84, 11-18.

22. Hirsch, P.R.; Mauchline, T.H. Who's who in the plant root microbiome? Nat. Biotechnol. 2012, 30, 961-962.

23. Köberl, M.; Ramadan, E.M.; Roßmann, B.; Staver, C.; Fürnkranz, M.; Lukesch, B.; Grube, M.; Berg, G. Using ecological knowledge and molecular tools to develop effective and safe biocontrol strategies. In Pesticides in the Modern World/Book 5; E-book: Rijeka, Croatia, 2012.

24. Van der Heijden, M.G.A.; Klironomos, J.N.; Ursic, M.; Moutoglis, P.; Streitwolf-Engel, R.; Boller, T.; Wiemken, A.; Sanders, I.R. Mycorrhizal fungal diversity determines plant biodiversity, ecosystem variability and productivity. Nature 1998, 396, 69-72.

25. Latz, E.; Eisenhauer, N.; Rall, B.C.; Allan, E.; Roscher, C.; Scheu, S.; Jousset, A. Plant diversity improves protection against soil-borne pathogens by fostering antagonistic bacterial communities. J. Ecol. 2012, 100, 597-604.

26. Opelt, K.; Berg, C.; Berg, G. The bryophyte genus Sphagnum is a reservoir for powerful and extraordinary antagonists and potentially facultative human pathogens. FEMS Microbiol. Ecol. 2007, 61, 38-53.

27. Berg, G.; Hartenberger, K.; Liebminger, S.; Zachow, C. Antagonistic endophytes from mistletoes as bio-resource to control plant as well as clean room pathogens. IOBC/wprs Bull. 2012, 79, $29-32$.

28. Zachow, C.; Berg, C.; Müller, H.; Meincke, R.; Komon-Zelazowska, M.; Druzhinina, I.S.; Kubicek, C.P.; Berg, G. Fungal diversity in the rhizosphere of endemic plant species of Tenerife (Canary Islands): Relationship to vegetation zones and environmental factors. ISME J. 2009, 3, 79-92.

29. Mazzola, M. Mechanisms of natural soil suppressiveness to soilborne diseases. Antonie Van Leeuwenhoek 2002, 81, 557-564.

30. Weller, D.M.; Raaijmakers, J.M.; McSpadden Gardener, B.B.; Thomashow, L.S. Microbial populations responsible for specific soil suppressiveness to plant pathogens. Annu. Rev. Phytopathol. 2002, 40, 309-348.

31. Mendes, R.; Kruijt, M.; de Bruijn, I.; Dekkers, E.; van der Voort, M.; Schneider, J.H.M.; Piceno, Y.M.; DeSantis, T.Z.; Andersen, G.L.; Bakker, P.A.; et al. Deciphering the rhizosphere microbiome for disease-suppressive bacteria. Science 2012, 332, 1097-1100.

32. Schmid, F.; Moser, G.; Müller, H.; Berg, G. Functional and structural microbial diversity in organic and conventional viticulture: Organic farming benefits natural biocontrol agents. Appl. Environ. Microbiol. 2011, 77, 2188-2191.

33. Köberl, M.; Müller, H.; Ramadan, E.M.; Berg, G. Desert farming benefits from microbial potential in arid soils and promotes diversity and plant health. PLoS One 2011, 6, e24452.

34. Grube, M.; Cardinale, M.; Vieira de Castro Junior, J.; Müller, H.; Berg, G. Species-specific structural and functional diversity of bacterial communities in lichen symbiosis. ISME J. 2009, 3, 1105-1115.

35. Ehlers, R.U. Regulation of Biological Control Agents; Springer: Heidelberg, Germany, 2011. 
36. Berg, G.; Eberl, L.; Hartmann, A. The rhizosphere as a reservoir for opportunistic human pathogenic bacteria. Environ. Microbiol. 2005, 7, 1673-1685.

37. Egamberdieva, D.; Kucharova, Z.; Davranov, K.; Berg, G.; Makarova, N.; Azarova, T.; Chebotar, V.; Tikhonovich, I.; Kamilova, F.; Validov, S.Z.; et al. Bacteria able to control foot and root rot and to promote growth of cucumber in salinated soils. Biol. Fertil. Soils 2011, 47, 197-205.

38. Roder, A.; Hoffmann, E.; Hagemann, M.; Berg, G. Synthesis of the compatible solutes glucosylglycerol and trehalose by salt-stressed cells of Stenotrophomonas strains. FEMS Microbiol. Lett. 2005, 7, 1853-1858.

39. Ryan, R.P.; Monchy, S.; Cardinale, M.; Taghavi, S.; Crossman, L.; Avison, M.B.; Berg, G.; van der Lelie, D.; Dow, J.M. The versatility and adaptation of bacteria from the genus Stenotrophomonas. Nat. Rev. Microbiol. 2009, 7, 514-525.

40. Alavi, P.; Starcher, M.R.; Zachow, C.; Müller, H.; Berg, G. Root-microbe systems: The effect and mode of interaction of Stress Protecting Agent (SPA) Stenotrophomonas rhizophila DSM14405 ${ }^{\mathrm{T}}$. Front. Plant Sci. 2013, 4, 141.

41. Alavi, P.; Starcher, M.R.; Thallinger, G.; Zachow, C.; Müller, H.; Berg, G. Stenotrophomonas comparative genomics reveal a fine line between beneficial and pathogenic bacteria. 2013, submitted.

(C) 2013 by the authors; licensee MDPI, Basel, Switzerland. This article is an open access article distributed under the terms and conditions of the Creative Commons Attribution license (http://creativecommons.org/licenses/by/3.0/). 